\title{
Prognostic factors for death and survival with or without complications in cardiac arrest patients receiving CPR within 24 hours of anesthesia for emergency surgery
}

This article was published in the following Dove Press journal:

Risk Management and Healthcare Policy

30 October 2014

Number of times this article has been viewed

\author{
Visith Siriphuwanun' \\ Yodying Punjasawadwong' \\ Worawut Lapisatepun' \\ Somrat Charuluxananan ${ }^{2}$ \\ Ketchada Uerpairojkit ${ }^{2}$ \\ 'Department of Anesthesiology, \\ Faculty of Medicine, Chiang Mai \\ University, Chiang Mai, Thailand; \\ ${ }^{2}$ Department of Anesthesiology, \\ Faculty of Medicine, Chulalongkorn \\ University, Bangkok, Thailand
}

Purpose: To determine prognostic factors for death and survival with or without complications in cardiac arrest patients who received cardiopulmonary resuscitation (CPR) within 24 hours of receiving anesthesia for emergency surgery.

Patients and methods: A retrospective cohort study approved by the Maharaj Nakorn Chiang Mai University Hospital Ethical Committee. Data used were taken from records of 751 cardiac arrest patients who received their first CPR within 24 hours of anesthesia for emergency surgery between January 1, 2003 and October 31, 2011. The reviewed data included patient characteristics, surgical procedures, American Society of Anesthesiologist (ASA) physical status classification, anesthesia information, the timing of cardiac arrest, CPR details, and outcomes at 24 hours after CPR. Univariate and polytomous logistic regression analyses were used to determine prognostic factors associated with the outcome variable. $P$-values of less than 0.05 were considered statistically significant.

Results: The outcomes at 24 hours were death (638/751, 85.0\%), survival with complications (73/751,9.7\%), and survival without complications (40/751, 5.3\%). The prognostic factors associated with death were: age between $13-34$ years $(\mathrm{OR}=3.08,95 \% \mathrm{CI}=1.03-9.19)$; ASA physical status three and higher $(\mathrm{OR}=6.60,95 \% \mathrm{CI}=2.17-20.13)$; precardiopulmonary comorbidity $(\mathrm{OR}=3.28$, $95 \% \mathrm{CI}=1.09-9.90)$; the condition of patients who were on mechanical ventilation prior to receiving anesthesia $(\mathrm{OR}=4.11,95 \% \mathrm{CI}=1.17-14.38)$; surgery in the upper abdominal site $(\mathrm{OR}=14.64,95 \%$ $\mathrm{CI}=2.83-75.82)$; shock prior to cardiac arrest ( $\mathrm{OR}=6.24,95 \% \mathrm{CI}=2.53-15.36)$; nonshockable electrocardiography $(\mathrm{EKG})$ rhythm $(\mathrm{OR}=5.67,95 \% \mathrm{CI}=1.93-16.62)$; cardiac arrest occurring in postoperative period $(\mathrm{OR}=7.35,95 \% \mathrm{CI}=2.89-18.74)$; and duration of CPR more than 30 minutes $(\mathrm{OR}=4.32,95 \% \mathrm{CI}=1.39-13.45)$. The prognostic factors associated with survival with complications were being greater than or equal to 65 years of age ( $\mathrm{OR}=4.30,95 \% \mathrm{CI}=1.13-16.42$ ), upper abdominal site of surgery ( $\mathrm{OR}=10.86,95 \% \mathrm{CI}=1.99-59.13$ ), shock prior to cardiac arrest (OR $=3.62,95 \% \mathrm{CI}=1.30-10.12)$, arrhythmia prior to cardiac arrest $(\mathrm{OR}=4.61,95 \% \mathrm{CI}=1.01-21.13)$, and cardiac arrest occurring in the postoperative period ( $\mathrm{OR}=3.63,95 \% \mathrm{CI}=1.31-10.02)$.

Conclusion: The mortality and morbidity in patients who received anesthesia for emergency surgery within 24 hours of their first CPR were high, and were associated with identifiable patient comorbidity, age, shock, anatomic site of operation, the timing of cardiac arrest, EKG rhythm, and the duration of CPR. EKG monitoring helps to identify cardiac arrest quickly and diagnose the EKG rhythm as a shockable or nonshockable rhythm, with CPR being performed as per the American Heart Association (AHA) CPR Guidelines 2010. The use of the fast track system in combination with an interdisciplinary team for surgery, CPR, and postoperative care helps to rescue patients in a short time.

Keywords: CPR, cardiac arrest, emergency surgery, prognostic factors, death, survival, survival with complications, mortality, morbidity

Risk Management and Healthcare Policy 2014:7 199-210

199

(c) (7) (5) 2014 Siriphuwanun et al. This work is published by Dove Medical Press Limited, and licensed under Creative Commons Attribution - Non Commercial (unported, v3.0) License. The full terms of the License are available at http://creativecommons.org/licenses/by-nc/3.0/. Non-commercial uses of the work are permitted without any further issions beyond the scope of the License are administered by Dove Medical Press Limited. Information on how to request permission may be found at: http://www.dovepress.com/permissions.php 


\section{Introduction}

Emergency surgery by its nature limits preoperative preparation, which can lead to increased risks of perioperative cardiac arrest. In fact, the frequency of cardiac arrest is reported more than three times higher than in elective cases, with subsequently higher mortality rates. ${ }^{1-6}$ Studies in a developed country, the United States of America, reported that more than half of all patients undergoing emergency surgery experienced episodes of cardiac arrest. ${ }^{6}$ In developing countries, ${ }^{2,7,8}$ the incidence of perioperative cardiac arrest and death in emergency surgery was higher than in developed countries over the past decade. ${ }^{1,9}$ A systematic review found that perioperative mortality was higher in developing countries than developed countries. ${ }^{10}$ Very high incidences of death were noted in some teaching hospitals in Thailand, especially in the Northern region. ${ }^{11}$

Cardiopulmonary resuscitation (CPR) helps to decrease mortality and morbidity in patients suffering from cardiac arrest. Previous studies show that CPR is the key to survival, and the success of the CPR procedure is best when the detection of the cardiac arrest occurs within 1 minute; early CPR begins within 4 minutes; early defibrillation within 5 minutes; and early advanced cardiovascular life support within 10 minutes performed by adequately trained CPR teams. ${ }^{12,13}$

Studies in developed countries found that factors predicting a good outcome for patients experiencing cardiac arrest included CPR performed in the emergency department, ${ }^{3,14}$ electrocardiography (EKG) rhythm before arrest (ventricular tachycardia/ventricular fibrillation in particular), ${ }^{15}$ short duration of CPR, ${ }^{14-16}$ and adequately trained resuscitation teams.${ }^{17}$ Factors that are common in patients who died or survived with complications after attempted resuscitation included: blood loss, ${ }^{18}$ suffering from hypotension before cardiac arrest, ${ }^{19}$ emergency surgery performed outside of the normal working hours, suffering from severe underlying disease,${ }^{20}$ suffering from severe conditions, ${ }^{16,21}$ and emergency surgery ${ }^{14,22}$ (especially trauma, ${ }^{16,20}$ cardiovascular surgery,,${ }^{19,22}$ abdominal aortic aneurysm, ${ }^{3}$ infant or elderly patients, ${ }^{20,23,24}$ myocardial ischemia, ${ }^{3}$ and delay in carrying out surgery). ${ }^{23}$

In developing countries, factors predicting survival after resuscitation were the duration of $\mathrm{CPR}$, where CPR was performed, and duration of intubation. ${ }^{25,26}$ Factors predicting death or survival with complications included low oxygen saturation, delay to admission, lack of equipment, American Society of Anesthesiologists (ASA) physical status class, ${ }^{5,22,27}$ anatomic site of surgery, EKG rhythm, ${ }^{28}$ trauma, and emergency surgery., ${ }^{4,522}$ Almost all previous studies in various regions did not focus on patients receiving anesthesia for emergency surgery in all anatomic sites of surgery, and only few studies focused specifically on the prognostic factors for each outcome of post-CPR in cardiac arrest patients during anesthesia. Therefore, this study was performed to determine the outcomes and prognostic factors of post-CPR in patients suffering cardiac arrest within 24 hours after receiving anesthesia for emergency surgery at Maharaj Nakorn Chiang Mai Hospital, a university teaching hospital in Northern Thailand.

\section{Patients and methods}

The study was a retrospective data review of patients who experienced cardiac arrests and underwent CPR within 24 hours of receiving anesthesia for emergency surgery at the Maharaj Nakorn Chiang Mai Hospital, Faculty of Medicine, Chiang Mai University, Northern Thailand. The present study was approved by the Ethical Committee of the Faculty of Medicine, Chiang Mai University.

Excluded from the study were patients who 1) had experienced one or more episodes of cardiac arrest with CPR prior to or during the emergency surgery; 2) patients who received topical anesthesia by surgeons; 3) patients who had monitored anesthesia care but did not receive anesthetic drug; 4) anesthetized patients whose surgery was cancelled for medical reasons; and 5) patients whose medical records were incomplete.

A total of 751 patients met the inclusion and exclusion criteria for cardiac arrest from January 1, 2003 and October 31, 2011. The data collected were preplanned by the anesthesia providers who recorded all relevant data from patients undergoing anesthesia for emergency surgery using the anesthesiology data collection form..$^{11}$ The data included patient characteristics such as sex, age, medication use or substance abuse, preanesthetic comorbidities, preoperative medical conditions, ASA physical status classification, anatomic site of operation, patient monitoring, anesthetic technique, airway management, administration of anesthesia, anesthetic agents used, and outcomes. The patients' clinical progress was documented from the start of anesthesia until 24 hours after the end of the operation. All preplanned data regarding CPR on those who suffered cardiac arrest were recorded on the data collection form for cardiac arrest events. ${ }^{11}$ The researcher and the research assistants were trained to standardize the data collection procedure to ensure that the collected data were reliable. Outcomes were checked by an anesthesiologist, a resident, and/or a surgeon for verification. For incomplete data, the 
researcher reviewed the charts after the CPR event as well as the details in the anesthesiology records, medical records, EKG, and laboratory reports; and added the compiled information where necessary. All of the relevant data were checked for any inconsistency and were edited by the researchers before being entered into the computer by the double-entry technique.

Prognostic factors predict the post-CPR outcomes in cardiac arrest patients by defining clinical and baseline characteristic variables of CPR performance that is objectively measurable and/or predict the outcome as death, or survival with or without complications. This study has a polytomous outcome and we have identified the prognostic variables for each outcome by using the survival outcomes as the reference groups.

The three patient outcomes investigated in this study were death, survival, and survival with complications. Death is defined when the patient dies within 24 hours of CPR (diagnosis of death by the physician, excluding death of patients who are organ donors, and brain death). Survival means that patients have returned to a normal baseline condition within 24 hours of receiving CPR, without complications caused by the cardiac arrest. Survival with complications is defined as surviving after resuscitation but having complications such as neurological (eg, brain death, coma, cerebrovascular accident, and convulsion); myocardial dysfunction (eg, suspected myocardial infarction and arrhythmia requiring treatment); acute renal failure; and bowel ischemia.

Descriptive statistics were used for analysis of the baseline characteristic data including age, sex, ASA physical status, current medication, personal history, and any comorbidities. Exact probability tests were used to analyze categorical variables, and analysis of variance (ANOVA) for continuous data to compare patients who died, survived, and survived with complications for at least 24 hours after CPR. Polytomous logistic regression analyses were performed using the survival group as a reference. Predictors associated with each outcome variable at $P<0.02$ were further analyzed by a stepwise multivariable generalized linear regression. The multicollinearity of all variables was examined using a bivariate correlation matrix. If any factors showed multicollinearity, only one of them was selected for further multivariate analysis. The data were presented by using multivariable relative odd ratios (OR), $95 \%$ confidence interval (CI). $P$-values of less than 0.05 were considered statistically significant. Analysis was carried out by STATA statistical software package (Stata Corp LP, College Station, TX, USA).

\section{Results}

This 9-year retrospective study found that the total number of patients undergoing emergency surgery was 46,624 cases, and $1.61 \%$ (751 cases) of them suffered cardiac arrest. Outcomes post-CPR were death $(638 / 751,85.0 \%)$, survival with complications $(73 / 751,9.7 \%)$, and survival (40/751, $5.3 \%$ ). Most patients had received general anesthesia and more than half of the patients received intensive anesthetic monitoring during anesthesia (Table 1). The average age of the total sample was $38.65 \pm 21.78$ years. Cardiac arrests occurring outside working hours led to a death rate twice as high as those occurring within working hours. Most patients were male. Cardiac arrests during the perioperative period led to a higher rate of survival. The return of spontaneous circulation (ROSC) in the death group was $23.8 \%$ and nonROSC was $76.2 \%$. The main causes of the cardiac arrest in each group was the severity of patients' conditions and those patients experiencing cardiovascular events were suffering from shock and arrhythmia immediately before cardiac arrest. Most patients who received CPR were shown to have a nonshockable EKG rhythm. Most patients were on endotracheal tubes with mechanical ventilation for life preservation, and received resuscitation drugs prior to receiving anesthesia, as shown in Table 2. In the perioperative period of cardiac arrest, the number of patient deaths within 24 hours is $78.3 \%(238 / 304), 40.8 \%$ (124/304) of these were deaths in perioperative period. The number of postoperative cardiac arrest cases that resulted in death within 24 hours was $89.5 \%$ (400/447), and the average time after the end of anesthesia until the occurrence of cardiac arrest was 9.0 \pm 7.1 hours. Moreover, we found that most patients in intensive care unit (293/400, 73.3\%) received full monitoring prior to their fatal cardiac arrest. The patients who had cardiac arrests in the postoperative period were found to develop various cardiopulmonary problems soon after the cessation of anesthesia. The majority of patients had hypotension (336, $75.2 \%$ ), and required an endotracheal tube for supported breathing $(407,91.1 \%)$, while some patients experienced blood loss more than $3,000 \mathrm{~mL}$ during surgery (32.2\%).

The univariate analysis found that death and survival with complications were associated with age between 13-34 years old, and greater than or equal to 65 years old; ASA physical status three and higher; upper intra-abdominal site of surgery; preoperative comorbidity (eg, cardiopulmonary, neurological, hematological conditions); cardiac arrest occurred in postoperative period, poor baseline hemodynamic conditions with shock, arrhythmias prior to cardiac arrest, nonshockable EKG rhythms, and duration of CPR $(P<0.02)$ 
Table I Baseline characteristics of post-CPR patients within 24 hours after anesthesia for emergency surgery (univariate analysis)

\begin{tabular}{|c|c|c|c|c|}
\hline \multirow[t]{2}{*}{ Characteristics } & \multicolumn{3}{|c|}{ Post-CPR outcomes } & \multirow[t]{2}{*}{$P$-value } \\
\hline & $\begin{array}{l}\text { Survival,c } \\
n=40 \text { (\%) }\end{array}$ & $\begin{array}{l}\text { Survival with } \\
\text { complications, } \\
\mathrm{n}=\mathbf{7 3}(\%)\end{array}$ & $\begin{array}{l}\text { Death within } \\
24 \text { hours of CPR, } \\
n=638(\%)\end{array}$ & \\
\hline Sex, male & $27(67.5)$ & $50(68.5)$ & $445(69.8)$ & 0.915 \\
\hline Age (years) & & & & 0.014 \\
\hline$\leq 2$ years & $3(7.5)$ & $6(8.2)$ & $34(5.3)$ & \\
\hline $3-12$ & $5(12.5)$ & $5(6.9)$ & $19(3.0)$ & \\
\hline $13-34$ & II (27.5) & $17(23.3)$ & $163(25.6)^{*}$ & \\
\hline $35-64$ & $17(42.5)$ & $22(30.1)$ & $265(4 \mid .5)$ & \\
\hline$\geq 65$ years & $4(10.0)$ & $23(31.5)^{*}$ & $157(24.6)$ & \\
\hline Mean \pm SD & $34.89 \pm 22.17$ & $45.87 \pm 27.09$ & $45.62 \pm 22.82$ & \\
\hline ASA physical status $\geq 3$ & $22(55.0)$ & $63(86.3)^{*}$ & $611(95.7)^{*}$ & $<0.001$ \\
\hline \multicolumn{5}{|l|}{ Anatomic site of surgery } \\
\hline Intracranial & $5(12.5)$ & $14(19.2)$ & $126(19.8)$ & 0.589 \\
\hline Intrathoracic & $6(15.0)$ & $7(9.6)$ & $45(7.1)$ & 0.152 \\
\hline Cardiovascular & $9(22.5)$ & $13(17.8)$ & $76(11.9)$ & 0.062 \\
\hline Upper intra-abdominal & $2(5.0)$ & $21(28.8)^{*}$ & $252(39.5)^{*}$ & $<0.001$ \\
\hline Lower intra-abdominal & 7 (I7.5) & $3(4.1)$ & $36(5.6)$ & 0.017 \\
\hline Ear, nose, and throat & $4(10.0)$ & $6(8.2)$ & $62(9.7)$ & 0.930 \\
\hline Extremities & $7(17.5)$ & $9(12.3)$ & $4 I(6.4)$ & 0.012 \\
\hline \multicolumn{5}{|l|}{ Preoperative comorbidity ${ }^{\mathrm{a}}$} \\
\hline Cardiopulmonary & $23(57.5)$. & $67(91.8)^{*}$ & $595(93.3)^{*}$ & $<0.001$ \\
\hline Neurological & $10(25.0)$ & $14(19.2)$ & $231(36.2)$ & 0.005 \\
\hline Hematological & II (27.5) & $35(47.9)$ & $352(55.2)$ & 0.002 \\
\hline Endocrine & $10(25.0)$ & II (I5.I) & $88(13.8)$ & 0.147 \\
\hline \multicolumn{5}{|l|}{ Personal history } \\
\hline Smoking $\geq 10$ pack-years & $\mathrm{I}(2.5)$ & $3(4.1)$ & $17(2.7)$ & 0.625 \\
\hline Previous anesthesia & $14(35.0)$ & $28(38.36)$ & $273(42.8)$ & 0.528 \\
\hline \multicolumn{5}{|l|}{ Anesthesia techniques } \\
\hline Non-GA ${ }^{b}$ & $2(5.0)$ & $\mathrm{I}(3.4)$ & I5 (2.4) & 0.371 \\
\hline GA/GA(TIVA) & $38(95.0)$ & $72(98.6)$ & $623(97.6)$ & \\
\hline Intensive anesthetic monitoring ${ }^{d}$ & $22(55.0)$ & $55(75.3)$ & $437(68.5)$ & 0.086 \\
\hline Duration time of anesthesia, mean \pm SD & $149.5 \pm \mid 24.4$ & $135.6 \pm 102.0$ & $124.9 \pm 92.6$ & 0.233 \\
\hline Estimated blood loss $(\mathrm{mL})$, mean \pm SD & $1,238.2 \pm 2,166.0$ & $\mathrm{I}, 162.3 \pm \mathrm{I}, 384.2$ & $1,806.5 \pm 2,058.9$ & $<0.001$ \\
\hline Total volume replacement $(\mathrm{mL})$, mean \pm SD & $2,118.9 \pm 2,766.7$ & $\mathrm{I}, 802.8 \pm \mathrm{I}, 559.4$ & $2,826.4 \pm 2,736.0$ & $<0.001$ \\
\hline Blood replacement $(\mathrm{mL})$, mean \pm SD & $1,490.8 \pm 1,520.8$ & $\mathrm{I}, 25 \mathrm{I} .9 \pm \mathrm{I}, 245.7$ & $1,512.6 \pm I, 436.6$ & 0.465 \\
\hline \multicolumn{5}{|l|}{ Type of volume replacement ${ }^{\mathrm{e}}$} \\
\hline Crystalloids & $19(47.5)$ & $19(26.0)$ & |7| (26.8) & 0.022 \\
\hline Colloids & $2(5.0)$ & $4(5.5)$ & $54(8.5)$ & 0.674 \\
\hline Crystalloids and colloids & $19(47.5)$ & $50(68.5)$ & $4 \mid 3(6 \mid .3)$ & 0.067 \\
\hline \multicolumn{5}{|l|}{ Type of blood replacement ${ }^{\mathrm{e}}$} \\
\hline Whole blood & $2(5.0)$ & $6(8.2)$ & $97(15.2)$ & 0.073 \\
\hline Packed red blood cells & $12(30.0)$ & $36(49.3)$ & $328(51.4)$ & 0.029 \\
\hline Fresh frozen plasma & $9(22.5)$ & $19(26.0)$ & $222(34.8)$ & 0.107 \\
\hline Platelets & $3(7.5)$ & $8(10.9)$ & $69(10.8)$ & 0.935 \\
\hline \multicolumn{5}{|l|}{ Time of cardiac arrest } \\
\hline Working hours (7.3I am-3.30 pm) & $18(45.0)$ & $25(34.3)$ & $213(33.4)$ & 0.327 \\
\hline Non-working hours (3.3I pm-7.30 am) & $22(55.0)$ & $48(65.8)$ & $425(66.6)$ & \\
\hline \multicolumn{5}{|l|}{ Anesthetic period time of cardiac arrest occurred } \\
\hline Perioperative period & $28(70.0)^{*}$ & $38(52.1)$ & $238(37.3)$ & $<0.001$ \\
\hline Postoperative period ${ }^{f}$ & $12(30.0)$ & $35(47.9)^{*}$ & $400(62.7)^{*}$ & \\
\hline \multicolumn{5}{|c|}{ Underlying hemodynamic conditions prior to cardiac arrest } \\
\hline Hypertension & $2(5.0)$ & $3(4.1)$ & $7(1.1)$ & 0.024 \\
\hline Shock/impending shock & $15(37.5)$ & $54(73.9)^{*}$ & $555(86.9)^{*}$ & $<0.001$ \\
\hline Ischemia/MI & $\mathrm{I}(2.5)$ & I ( ( .4$)$ & $17(2.7)$ & 1.000 \\
\hline Arrhythmia & $7(17.5)$ & $\mathrm{II}(\mathrm{I} 5 . \mathrm{I})^{*}$ & $50(7.8)$ & 0.019 \\
\hline
\end{tabular}


Table I (Continued)

\begin{tabular}{|c|c|c|c|c|}
\hline \multirow[t]{2}{*}{ Characteristics } & \multicolumn{3}{|c|}{ Post-CPR outcomes } & \multirow[t]{2}{*}{$P$-value } \\
\hline & $\begin{array}{l}\text { Survival,c } \\
n=40 \text { (\%) }\end{array}$ & $\begin{array}{l}\text { Survival with } \\
\text { complications, } \\
\mathrm{n}=73(\%)\end{array}$ & $\begin{array}{l}\text { Death within } \\
24 \text { hours of CPR, } \\
n=638(\%)\end{array}$ & \\
\hline \multicolumn{5}{|l|}{ Initial EKG rhythm } \\
\hline Shockable rhythm ${ }^{g}$ & $12(30.0)$ & $12(16.4)$ & $43(6.7)$ & $<0.001$ \\
\hline Nonshockable rhythm ${ }^{\mathrm{h}}$ & $28(70.0)$ & $61(83.6)$ & $595(93.3)^{*}$ & \\
\hline
\end{tabular}

Notes: a One patient had more than one comorbidity; ${ }^{b}$ non-GA includes monitored anesthesia care, spinal block, epidural block, caudal block, and brachial block anesthesia; 'survival is a comparable group ; Intensive monitoring such as EKG, pulse oximetry, capnograph monitoring, central venous pressure (CVP), and arterial line blood pressure; eone patient had more than one type of volume replacements; ${ }^{f}$ postoperative period (recovery room [18, 4.0\%], intensive care unit [320, 7I.6\%], and ward [109, 24.4\%]); ${ }^{g}$ ventricular fibrillation/ventricular tachycardia (VF/VT); hasystole, pulseless electrical activity; bradycardia and tachycardia EKG rhythm. *indicates univariate logistic factors related to each outcome.

Abbreviations: SD, standard deviation; OR, odds ratio; $\mathrm{Cl}$, confidence interval; mL, milliliter; ASA, American Society of Anesthesiologists; CPR, cardiopulmonary resuscitation; GA, general anesthesia; TIVA, total intravenous anesthesia; MI, myocardial infarction; EKG, electrocardiography.

(Table 1). Most anesthetic drugs did not affect post-CPR outcomes except for cisatracurium which was shown to be significantly associated with death (Table 3 ).

The patients who were on mechanical ventilation prior to receiving anesthesia and patients who were given vasoactive and antiarrhythmic drugs prior to cardiac arrest (eg, dopamine, dobutamine, levophed, and epinephrine) had a higher risk of death within 24 hours of CPR, and of developing complications if they survived (Table 2). If a patient had resuscitation drugs such as epinephrine and ephedrine administered during CPR the survival rate increased. Meanwhile, if a patient who was in a poor condition was also on vasoactive drugs continuously during CPR (eg, dopamine or levophed) the death rate was two times higher than in those did not receive vasoactive drugs (Table 3).
Prognostic factors associated with death in comparison to survival in the polytomous logistic regression analysis were age between 13 and 34 years $(\mathrm{OR}=3.08,95 \%$ $\mathrm{CI}=1.03-9.19)$; ASA physical status three and higher ( $\mathrm{OR}=6.60,95 \% \mathrm{CI}=2.17-20.13$ ); precardiopulmonary comorbidity ( $\mathrm{OR}=3.28,95 \% \mathrm{CI}=1.09-9.90)$; the condition of patients who were on mechanical ventilation prior to receiving anesthesia ( $\mathrm{OR}=4.11,95 \% \mathrm{CI}=1.17-14.38)$; upper abdominal site of surgery $(\mathrm{OR}=14.64,95 \% \mathrm{CI}$ $=2.83-75.82)$; shock prior to cardiac arrest $(\mathrm{OR}=6.24$, 95\% CI =2.53-15.36); nonshockable EKG rhythms (OR $=5.67,95 \% \mathrm{CI}=1.93-16.62$ ), cardiac arrest occurring in the postoperative period $(\mathrm{OR}=7.35,95 \% \mathrm{CI}=2.89-18.74)$; and the duration of CPR being longer than 30 minutes (OR $=4.32,95 \% \mathrm{CI}=1.39-13.45)$. While, the prognostic factors associated with survival with complications were age greater

Table 2 Previous treatment agents, monitoring, and CPR performed in patients suffering cardiac arrest following anesthesia for emergency surgery (univariate analysis)

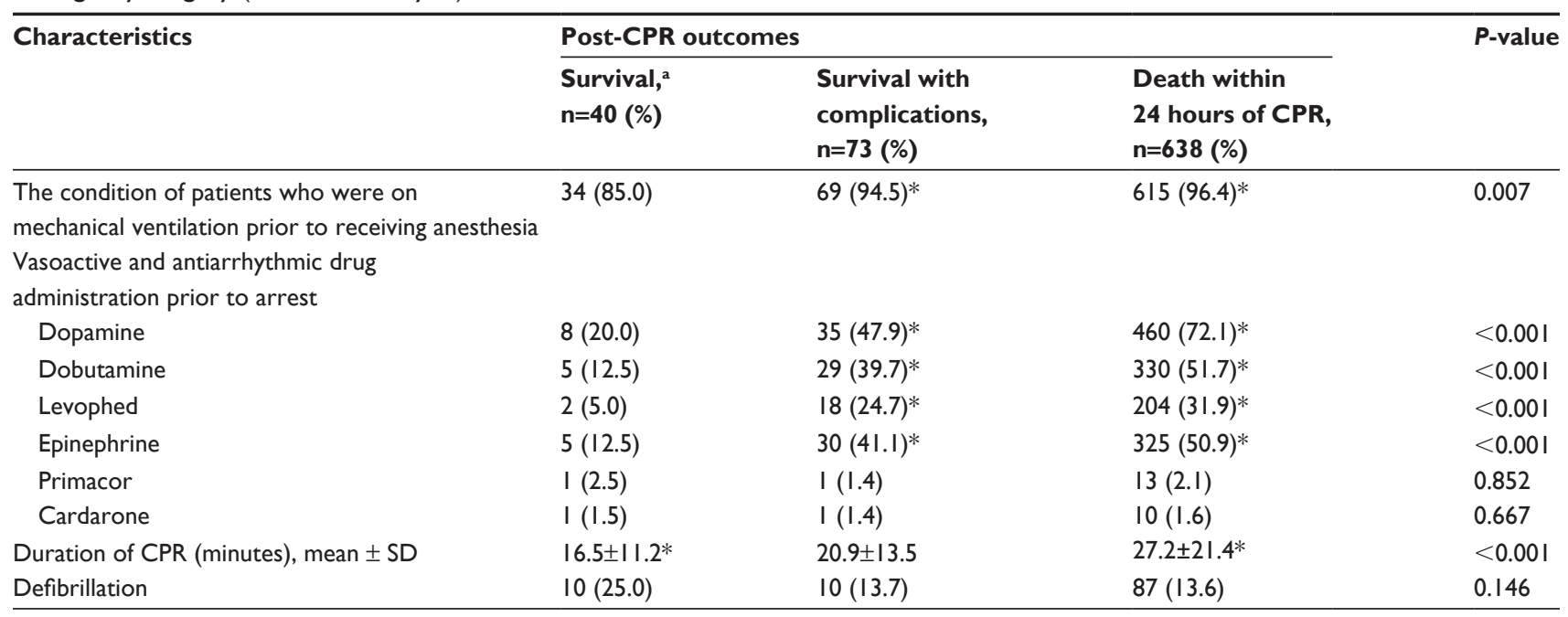

Notes: aSurvival is a comparable group. *Indicates univariate logistic factors related to each outcome.

Abbreviations: SD, standard deviation; CPR, cardiopulmonary resuscitation. 
Table 3 Anesthetic agents used, treatment of patients, and CPR management in emergency surgery patients suffering cardiac arrest (univariate analysis)

\begin{tabular}{|c|c|c|c|c|}
\hline \multirow[t]{2}{*}{$\overline{\text { Characteristics }}$} & \multicolumn{3}{|c|}{ Post-CPR outcomes } & \multirow[t]{2}{*}{$P$-value } \\
\hline & $\begin{array}{l}\text { Survival, }{ }^{a} \\
n=40(\%)\end{array}$ & $\begin{array}{l}\text { Survival with } \\
\text { complications, } \\
\text { n=73 (\%) }\end{array}$ & $\begin{array}{l}\text { Death within } \\
24 \text { hours of CPR, } \\
n=638(\%)\end{array}$ & \\
\hline \multicolumn{5}{|l|}{ Anesthetic agents } \\
\hline Thiopental & $14(35.0)$ & $15(20.6)$ & $96(15.1)$ & 0.005 \\
\hline Propofol & $8(20.0)$ & II (I5.I) & $48(7.5)$ & 0.005 \\
\hline Ketamine & I (2.5) & $10(13.7)$ & $99(15.5)$ & 0.057 \\
\hline Etomidate & $2(5.0)$ & $4(5.5)$ & $76(11.9)$ & 0.127 \\
\hline Midazolam & $19(47.5)$ & $36(49.3)$ & $37 \mid(58.2)$ & 0.158 \\
\hline Diazepam & $2(5.0)$ & $2(2.7)$ & $13(2.04)$ & 0.232 \\
\hline Nitrous oxide & $10(25.0)$ & $69(10.8)$ & $12(16.4)$ & 0.020 \\
\hline Isoflurane & $15(37.5)$ & $21(28.8)$ & $139(21.8)$ & 0.041 \\
\hline Sevoflurane & $12(30.0)$ & $20(27.4)$ & $184(28.9)$ & 0.940 \\
\hline Succinylcholine & $6(15.0)$ & $7(9.6)$ & $4 \mid(6.4)$ & 0.079 \\
\hline Pancuronium & $10(25.0)$ & $19(26.0)$ & $164(25.6)$ & 1.000 \\
\hline Atracurium & $4(10.0)$ & $5(6.9)$ & $4 \mid(6.4)$ & 0.569 \\
\hline Cisatracurium & $6(15.0)$ & $7(9.6)$ & $154(24.2)$ & 0.006 \\
\hline Vecuronium & $9(22.5)$ & $28(38.4)$ & $166(26.1)$ & 0.070 \\
\hline Levobupivacaine & $4(10.0)$ & $5(6.9)$ & $29(4.6)$ & 0.175 \\
\hline Morphine & I (2.5) & $2(2.7)$ & $16(2.5)$ & 0.888 \\
\hline Fentanyl & $32(80.0)$ & $60(82.2)$ & $479(75.2)$ & 0.356 \\
\hline \multicolumn{5}{|l|}{ Resuscitation drugs } \\
\hline Epinephrine & $39(97.5)$ & $65(89.0)$ & $526(82.6)$ & 0.013 \\
\hline Atropine & $20(50.0)$ & $31(42.5)$ & $252(39.5)$ & 0.377 \\
\hline Ephedrine & $12(30.0)^{*}$ & $13(17.8)$ & $61(9.6)^{*}$ & $<0.001$ \\
\hline Calcium gluconate & $9(22.5)$ & $31(42.5)$ & $246(38.6)$ & 0.088 \\
\hline $\mathrm{NaHCO}_{3}$ & $19(47.5)$ & $4 I(56.2)$ & $360(56.4)$ & 0.539 \\
\hline \multicolumn{5}{|c|}{ Vasoactive and antiarrhythmic } \\
\hline \multicolumn{5}{|c|}{ drugs infusion during CPR } \\
\hline Dopamine & II (27.5) & $37(50.7)^{*}$ & $408(64.1)^{*}$ & $<0.001$ \\
\hline Dobutamine & $3(7.5)$ & $5(6.8)$ & $32(5.0)$ & 0.525 \\
\hline Levophed & $16(40.0)$ & $43(58.9)^{*}$ & $473(74.4)^{*}$ & $<0.001$ \\
\hline Epinephrine & $22(55.0)$ & $50(68.5)$ & $440(69.2)$ & 0.178 \\
\hline
\end{tabular}

Notes: aSurvival is a comparable group. *Indicates univariate logistic factors related to each outcome.

Abbreviations: CPR, cardiopulmonary resuscitation.

than or equal to 65 years $(\mathrm{OR}=4.30,95 \% \mathrm{CI}=1.13-16.42)$; upper abdominal site of surgery $(\mathrm{OR}=10.86,95 \% \mathrm{CI}=1.99$ 59.13); shock prior to cardiac arrest $(\mathrm{OR}=3.62,95 \% \mathrm{CI}$ $=1.30-10.12)$; arrhythmias prior to cardiac arrest $(\mathrm{OR}=4.61$, $95 \% \mathrm{CI}=1.01-21.13)$; and cardiac arrest occurring in postoperative period $(\mathrm{OR}=3.63,95 \% \mathrm{CI}=1.31-10.02)(P$-value $<0.05$ ) (Table 4).

\section{Discussion}

Recently, many studies have been undertaken regarding the short- and long-term outcomes of CPR. These studies have identified some of factors affecting mortality and morbidity, but all of these studies were conducted with planned preoperative preparation before receiving anesthesia and surgery. 7,18,22,27 These studies did not identify patients who needed anesthesia for emergency surgery.
A total incidence of cardiac arrest in the present study was 161 per 10,000 cases $(751$ in 46,624). Post-CPR outcomes within the 24-hour period were death $(85.0 \%)$, survival (5.3\%), and survival with complications (9.7\%). This showed a higher death rate than studies in other teaching hospitals in Thailand; which included cases of geriatric patients receiving anesthesia, ${ }^{4,27}$ a study in the medical care unit, ${ }^{25}$ a study in heart surgery, ${ }^{22}$ and pediatric surgery. ${ }^{29}$ Compared to developed countries, only one study involving trauma cases had a higher mortality rate at 24 hours than our findings. ${ }^{30}$ In addition, our results had a lower survival rate than a systematic review held in USA, which showed survival rates ranging from $15 \%$ to $20 \% .{ }^{31}$ A systematic review in Brazil had similar findings, which concluded that the mortality rates in developing countries were higher than in developed countries over the past decade. ${ }^{32,33}$ 
Table 4 Multivariable relative odd ratios and 95\% confidence interval of post-CPR outcomes in emergency surgery patients' characteristics for death, survival, and survival with complications, from polytomous logistic regression (comparing to survival group)

\begin{tabular}{|c|c|c|c|c|c|c|}
\hline \multirow[t]{2}{*}{ Post-CPR characteristics } & \multicolumn{3}{|c|}{ Death within 24 hours of CPR } & \multicolumn{3}{|c|}{ Survival with complications } \\
\hline & OR & $95 \% \mathrm{Cl}$ & $P$-value & OR & $95 \% \mathrm{Cl}$ & $P$-value \\
\hline \multicolumn{7}{|l|}{ Age (years) } \\
\hline$\leq 2$ & 2.47 & $0.4 I-14.85$ & 0.324 & 3.85 & $0.56-26.29$ & 0.170 \\
\hline $3-12$ & 0.77 & $0.16-3.70$ & 0.749 & $\mathrm{I} .84$ & $0.34-10.06$ & 0.482 \\
\hline $13-34$ & 3.08 & $1.03-9.19$ & 0.044 & 3.09 & $0.92-10.43$ & 0.069 \\
\hline $35-64$ & 1.00 & & & 1.00 & & \\
\hline$\geq 65$ years & 2.80 & $0.8 I-9.65$ & 0.103 & 4.30 & $1.13-16.42$ & 0.033 \\
\hline ASA physical status $\geq 3$ & 6.60 & $2.17-20.13$ & 0.001 & 2.34 & $0.67-8.22$ & 0.175 \\
\hline Precardiopulmonary comorbidity & 3.28 & $1.09-9.90$ & 0.035 & 3.49 & $0.94-12.95$ & 0.062 \\
\hline $\begin{array}{l}\text { The condition of patients who were on mechanical ventilation } \\
\text { prior to receiving anesthesia }\end{array}$ & 4.11 & $1.17-14.38$ & 0.027 & 3.02 & $0.66-13.87$ & 0.155 \\
\hline Upper abdominal site of surgery & 14.64 & $2.83-75.82$ & 0.001 & 10.86 & $1.99-59.13$ & 0.006 \\
\hline \multicolumn{7}{|l|}{ Underlying hemodynamic conditions prior to cardiac arrest } \\
\hline Shock/impending shock & 6.24 & $2.53-15.36$ & $<0.001$ & 3.62 & $1.30-10.12$ & 0.014 \\
\hline Arrhythmia & 3.84 & $0.90-16.43$ & 0.069 & 4.61 & $1.01-21.13$ & 0.049 \\
\hline Nonshockable EKG rhythma & 5.67 & $1.93-16.62$ & 0.002 & 2.80 & $0.85-9.23$ & 0.090 \\
\hline Cardiac arrest occurring in postoperative period ${ }^{\mathrm{b}}$ & 7.35 & $2.89-18.74$ & $<0.001$ & 3.63 & $1.31-10.02$ & 0.013 \\
\hline CPR duration more than 30 minutes & 4.32 & $1.39-13.45$ & 0.012 & 2.69 & $0.79-9.20$ & 0.114 \\
\hline
\end{tabular}

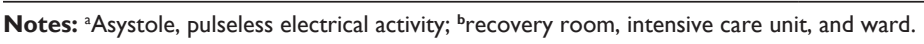

Abbreviations: ASA, American Society of Anesthesiologists; OR, odds ratio; Cl, confidence interval; CPR, cardiopulmonary resuscitation; EKG, electrocardiography.

However, high mortality in our study was probably due to the severity of the condition of the patients prior to CPR, the location where cardiac arrest occurred, and the time before cardiac arrest. The data show that occurrence of cardiac arrest was twice as high during non-working hours than in normal working hours. The main cause of cardiac arrest in each group was the condition of the patients before and during surgery, where initial signs of cardiovascular and respiratory events were shock and arrhythmia prior to cardiac arrest. In most cases, patients were on an endotracheal tube with mechanical ventilation and receiving resuscitation drugs prior to receiving anesthesia. These are big challenges for anesthetic teams, surgeons, and CPR teams when assessing the patients for emergency surgery in the first place.

\section{Prognostic factors predicting death}

Our study shows that being in the age group of 13-34 years is a significant predictor of death. It is in contrast to a recent study that investigated blunt trauma cases at an urban trauma center ${ }^{20}$ where it was found that the elderly had a high mortality rate. But this study included only the acute trauma patients for analysis and also the difference in the severity of their characteristic data. Meanwhile, our study was significantly in line with a study carried out in trauma patients aged younger than 18 years, who were found to have a lower survival rate. ${ }^{16}$ Our data show that young adults who were designated as ASA class three and higher (89.5\%) and whose anatomic site of the surgery was the upper abdominal site (43.5\%) had a high blood loss during surgery (mean $\pm \mathrm{SD}=1,954.3 \pm 1,900.7 \mathrm{~mL}$ ). The analysis of demographic data of the patients in each year showed that most of the patients who were admitted for emergency surgery resulting in death as an outcome had severe symptoms and high frequency of cardiac arrests at specific times of the year, eg, during festival celebrations. Many accidents involved driving a vehicle whilst under the influence of alcohol, the frequency of which increased dramatically three times a year during the festival celebrating, events such as New Year's Eve, Songkran Festival, and Loy Krathong Festival. Surgery involving patients with a high risk of extreme blood loss is a very difficult undertaking. Even when we have a process to help patients in crisis, the strategy set to reduce mortality whilst experiencing the high frequency of cases during festivals would not be easy. This requires the cooperation of many sectors; both in and outside the hospital. Hospitals must have a stand-by surgery room, additional teams, and larger stocks of blood available during the festival periods. The "Safety first" promotion policy should be as stringent as possible while enforcing traffic laws and municipal liquor range forecast. A campaign to prevent drunk driving during the festivals should be a priority and comply with legal requirements.

Consistent with other studies, ${ }^{5,18,23}$ our present study also found that patients with ASA physical status greater than or equal to class 3 have a high death rate, which is higher than the rate found in three studies carried out in Thailand. ${ }^{4,22,27}$ This had been confirmed by a systematic review of perioperative 
anesthesia in both developed countries and developing countries, where it was found that the increase in a patient's ASA physical status was a significant factor leading to increased mortality over time. 10,32,33 $^{2}$

The data obtained in the present study includes many factors involved in death in emergency patients with severe injuries. Most patients who died were in shock before suffering cardiac arrest (86.9\%). The underlying conditions were unstable cardiopulmonary (93.3\%), and hematological problems $(55.2 \%)$. The anatomic sites of surgery were upper abdominal (39.5\%), intracranial (19.8\%), and cardiovascular (11.9\%). Many patients suffered from substantial blood loss during surgery (mean $\pm \mathrm{SD}=1,806.5 \pm 2,058.9 \mathrm{~mL}$ ). It is a challenge for the interdisciplinary team to coordinate care for patients, they require a system that is quick and effective especially for patients with a high risk of mortality. Such a system is required not only for the anesthetic team, but also for the staff in the critical care unit, both before and after the surgery.

The results from this study demonstrate an important relationship between precardiopulmonary comorbidity and mortality where patients had mortality rates three times greater with precardiopulmonary comorbidity compared to those who did not have any. Four studies from developing countries support our findings, especially the two from Thailand, ${ }^{22,25}$ and others from India, ${ }^{34}$ and Kenya. ${ }^{35}$ Our results show a more remarkable death rate than other studies (96.4\%) observed in patients who were on mechanical ventilation. The remainder were related to cardiovascular causes of arrest, especially arrhythmias prior to cardiac arrest. This correlates with studies performed in developed countries, which found that an arrhythmia is a cause of cardiac arrest and death., ${ }^{3,36}$ Similarly, in Thailand, cardiovascular disease was found to be strongly correlated with high mortality. ${ }^{13,26,37}$ Therefore, the evaluation of the cardiovascular and respiratory systems as well as overall condition, including EKG monitoring prior to surgery and in the postoperative period are important especially in patients who had substantial blood loss and were elderly.

In addition, the condition of patients who were on mechanical ventilation prior to receiving anesthesia was another factor affecting mortality. Our evidence was consistent with a study in a tertiary care center in Pakistan, ${ }^{14}$ where it was ascertained that patients who were not intubated prior to cardiac arrest had the best outcome after CPR. A previous study ${ }^{15}$ in Spain has shown that children undergoing mechanical ventilation had a higher death rate. Our results show a significantly higher death rate than other studies because our patients had more respiratory problems prior to receiving anesthesia. Among the patients who died after cardiac arrest, $90 \%$ were intubated and on mechanical ventilation by indication, to preserve life, prior to anesthesia. Furthermore, cardiac arrest in the postoperative period resulted in the patient requiring an endotracheal tube to support respiration soon after anesthesia (91.1\%). It is necessary to provide excellent care and monitoring such as end tidal $\mathrm{CO}_{2}, \mathrm{O}_{2}$ saturation, and mechanical ventilation in both the peri- and postoperative periods.

Interestingly, our study found that surgery in the upper abdominal site is associated with a 15 times higher mortality rate, which is consistent with the findings at an university hospital in Thailand. ${ }^{4}$ The high mortality rates in the current study may be due to the effect of many surgical problems - abdominal trauma in particular. The abdominal trauma involves bleeding, contusions or blood losses in the abdominal cavity, and these patients' condition were highly correlated with multiple injuries. ${ }^{9,19}$

The data related to shock prior to cardiac arrest gave results of a six times higher mortality rate, which is also consistent with the findings at a university hospital in Thailand. ${ }^{11}$ However, the high mortality rates in patients experiencing shock prior to anesthesia in our finding may also correlate with the anatomic site of surgery. In particular, $70 \%$ of patients who underwent surgery of the upper abdomen experienced trauma and such results also had a high correlation with the number of patients who had high blood loss. In these cases assessing fluid and/or blood replacement is very difficult. Some patients had been treated with vasoactive and/or antiarrhythmic drugs before cardiac arrest. These findings were consistent with many recent studies conducted in Spain and Germany. Case reports from Australia showed that accident patients in shock with the ongoing treatment using vasoactive drugs, whilst suffering from multiple injuries, also had a poor outcome after CPR..$^{15,19,21}$ This is strongly supported by a study conducted at an university hospital in Thailand, which found that actively bleeding patients with uncontrolled hemodynamic shock who underwent anesthesia had high mortality rates. ${ }^{28}$

Consistent with findings from other studies, ${ }^{15,38,39}$ our results demonstrate an important relationship between a nonshockable EKG rhythm and an outcome resulting in death. This result is nearly six times higher when compared with a shockable rhythm. This corresponded with the results in Hong Kong, ${ }^{36} \mathrm{UK},{ }^{40}$ and Thailand, ${ }^{28}$ where patients with ventricular fibrillation/ventricular tachycardia (VF/VT) rhythms receiving early defibrillation had the best outcomes when compared to patients with an asystole and a pulseless electrical activity in EKG rhythm. 
From the evidence of the current study and others, ${ }^{41,42}$ we emphasize the importance of American Heart Association (AHA) CPR Guidelines $2010 .{ }^{12} \mathrm{CPR}$ patients receive a differential diagnosis by monitoring their EKG in cases of cardiac arrest when the EKG rhythm was interpreted as VF/VT thus requiring defibrillation (shockable), where there is a greater chance of survival than for a nonshockable rhythm. The resuscitator must have a detailed knowledge of resuscitation drugs, automated external defibrillators and pacemakers, as well as other factors that may reduce the chance of mortality when correctly managed.

Several studies have investigated the effect of the place where CPR is performed on patient outcomes. ${ }^{14,25}$ Their results corresponded with our findings, where CPR in the postoperative period was a significant factor for death. Two studies carried out at a university hospital in Turkey, ${ }^{43}$ and a tertiary care center in Pakistan, ${ }^{14}$ show that CPR performed in operating rooms and monitored areas, increased the chances of survival. A good outcome during the perioperative period was shown in our results because team responses in critical situations were prompt, dealing with the CPR situation quickly and efficiently. In the postoperative period, patients had instability in cardiovascular and respiratory systems after anesthesia where $75.2 \%$ (336) of patients had hypotension and $34 \%$ had cardiopulmonary-related deaths. AHA CPR Guidelines $2010^{12}$ training for the hospital personnel in all departments of the hospital improved patient outcomes. Also the prompt provision of intensive monitoring for patients in the postoperative care unit ensures more positive outcomes.

The final factor affecting death in the present study was a duration of CPR of more than 30 minutes. Consistent with a study in Thailand, ${ }^{37}$ and other studies carried out in developed countries and in developing countries, ${ }^{15,16,36}$ these studies showed that a duration of CPR ranging from 10-20 minutes increases the chance of initial survival. Therefore, we recommend following AHA CPR Guidelines $2010^{12}$ which focus on early "C-A-B", chest compression whenever cardiac arrest is detected in tandem with the evaluation of airway and circulatory systems, and adequate and constant monitoring using EKG, noninvasive blood pressure, and end tidal $\mathrm{CO}_{2}$ to detect EKG rhythm and ensure the success of ROSC. ${ }^{12}$

\section{Prognostic factors predicting survival with complications}

Recent studies found that elderly patients who underwent surgery had a high incidence of cardiac arrest and a high morbidity rate..$^{4,13,20,40}$ In this study, we demonstrated that patients of 65 years of age or more had an increased morbidity rate when compared to young adults. These results show more pronounced effects of age on survival with complications than other studies in elderly patients conducted in Thailand ${ }^{2}$ and Brazil. ${ }^{3}$ Relatively high postsurgical complications of CPR in our elderly patients showed correlation with several factors. These factors include precardiopulmonary comorbidity (91.8\%), high ASA physical status (95.6\%), and being in shock prior to cardiac arrest (84.2\%). Most patients were on an endotracheal tube with ventilator support (95.6\%). Systematic reviews in Brazil found that a patient with airway problems was also prone to high morbidity rates. ${ }^{32,33}$ Similarly, a study in Thailand ${ }^{25}$ showed that patients with respiratory problems have higher risks of developing complications after CPR.

Furthermore, the anatomic site of surgery in the elderly was severe high in regards to complications when compared to that of young adults. The most common procedure in emergency surgery in elderly patients involved upper abdominal and vascular surgeries, which were mainly to treat peritonitis, peptic ulcer perforation, and abdominal aortic aneurysms. These patients had higher risks of developing chronic diseases as they had preoperative comorbidities such as arrhythmia, sepsis, and diabetes mellitus and some patients were taking resuscitation drugs prior to surgery. Although postoperative cardiac arrest in some elderly patients did not lead to death, it led to high levels of complications. Hence, the elderly patients require a system that is quick and effective, not only during CPR but also in post-CPR care as well.

In our study, upper abdominal surgery was associated with eleven times higher post-CPR survival with complications, which is consistent with the results at a university hospital in Thailand. ${ }^{4}$ The high morbidity rates in upper abdominal surgery patients may be affected by the type of surgery particularly the abdominal trauma surgery. Studies in a developing country ${ }^{44}$ and developed countries ${ }^{30,45}$ confirm that abdominal trauma cases led to significantly higher complications. This was confirmed by many studies conducted in Spain, ${ }^{15}$ Brazil, ${ }^{1}$ and Germany, ${ }^{21}$ while case reports from Australia ${ }^{19}$ added that patients with abdominal injuries and shock had a poor outcome after CPR. This finding is strongly supported by a study in a university hospital in Thailand, which found that abdominal surgery patients had a high cardiac arrest rate ${ }^{46}$ and also had high levels of post-CPR complications. ${ }^{28}$

According to the present study, patients in shock prior to cardiac arrest had a very high risk of having complications, although they survived. Emergency surgery patients may be 
hemodynamically unstable and may have been treated with a resuscitation drug. Such results were observed clearly in our study, but we also found that patients who were in shock before cardiac arrest were three times more likely to survive with complications. This was consistent with other studies which reported that patients in shock after accidents had a poor outcome after CPR. ${ }^{15,19,21}$ This is strongly supported by a study carried out at a university hospital in Thailand, which found that patients in shock undergoing anesthesia had high complications. ${ }^{28,46}$

Among various cardiovascular causes of cardiac arrest, an arrhythmia is one of the significant factors leading to survival with complications. This corresponds to studies in some developed countries, which found that an arrhythmia is a cause of cardiac arrest and morbidity. ${ }^{3,36}$ Similarly, in a developing country, Thailand, cardiovascular disease was found to be a strong predictor of post-CPR survival with complications. However, if the arrhythmia is promptly treat it can be reverse to normal in a short time. ${ }^{13,26}$ This is supported by our results showing that arrhythmias was not the direct cause of death. This study, therefore, recommends that care for patients with a high risk of these predictors should include EKG monitoring for arrhythmia both during surgery and the postoperative period. This is particularly important in patients who have high risks of experiencing substantial blood loss during surgery and also in elderly patients with cardiopulmonary comorbidity.

Another prognostic factor was suffering a cardiac arrest in the postoperative period, which was associated with survival with complications. Reports from Turkey ${ }^{43}$ and Pakistan ${ }^{14}$ showed that performing CPR in operating rooms and the monitored areas decreased morbidity. In fact, in the postoperative period, some patients have many high-risk factors of cardiac arrest and complications of the cardiopulmonary system that will affect the major surgery and cause blood loss during surgery. This result was found the severe condition in cardiovascular system at time of the end of anesthesia (eg, hypotension [75.2\%], patients with blood loss of more than 3,000 mL during surgery [32.2\%]). These are challenges for postoperative teams who must adhere to the practice guidelines for risk management and resuscitation.

Relatively high mortality and morbidity within 24 hours of CPR in the present study should be of concern to the interdisciplinary teams and resuscitators. The finding that $9.7 \%$ of patients survived with complications after CPR is also of great concern. In the long term, these patients as a group need to be given post-CPR care and a long-term care plan after getting discharged in order to make the overall recovery time shorter. We recommend the AHA CPR Guidelines 2010 which involved: managing of hypothermia, adequate respiratory support, metabolic disorder treatment, proper treatment of hemodynamic instability, effective postoperative care, and resolving the $5 \mathrm{Hs}$ "hypovolemia, hypothermia, hypo/ hyperkalemia, hydrogen ion (acidosis), hypoxia" and the 5Ts "tension pneumothorax, tamponade, toxin, thrombosis, and thrombosis", and finally, enhancing the chances of a more positive outcome of a cardiac arrest. ${ }^{12}$

Our study had several limitations. During the 9-year period of this retrospective study, the CPR practice guidelines had been updated from the 2005 algorithm to the new guidelines in 2010. These changes in guidelines would have affected the results of this study. Additionally, our study was carried out using a retrospective study where occasionally some important data were missing. This may have led to no significance for some variables in the analysis. Furthermore, this study was conducted in one hospital, so our results may not be generalized and applied to other different settings. However, the current study has a strength in the data collection as, despite being a retrospective study, this study followed up patients suffering cardiac arrest at 24 and 48 hours after anesthesia. All data were reviewed by independent editors and all patients who suffered cardiac arrest were assessed on a monthly basis. This information was verified by the anesthesiologists and anesthetic nurses for accuracy before being entered into the database.

\section{Conclusion}

Patients in their first 24 hours post-CPR in emergency surgery, are shown to have high mortality and morbidity. The factors that affect the outcomes following early peri- and postoperative cardiac arrest are identifiable patient comorbidity, age, shock, anatomic site of operation, location of cardiac arrest, EKG rhythm and duration of CPR. Monitoring the EKG is helpful in initially identifying problems and it should be followed by adherence with the AHA CPR Guidelines 2010, and the fast track system in cooperation with interdisciplinary teams for surgery, CPR, and postoperative care over a short period of time.

\section{Acknowledgments}

This study has been supported by a grant from the Faculty of Medicine, Maharaj Nakorn Chiang Mai Hospital, Chiang Mai University. The authors would like to thank the Director of Maharaj Nakorn Chiang Mai Hospital, the team's advisor and the Department of Anesthesiology for the use of the data. 


\section{Disclosure}

The authors report no conflicts of interest in this work.

\section{References}

1. Braz LG, Modolo NS, do Nascimento P, et al. Perioperative cardiac arrest: a study of 53,718 anaesthetics over $9 \mathrm{yr}$ from a Brazilian teaching hospital. Br J Anaesth. 2006;96(5):569-575.

2. Tamdee D, Charuluxananan S, Punjasawadwong Y, et al. Factors related to 24-hour perioperative cardiac arrest in geriatric patients in a Thai university hospital. J Med Assoc Thai. 2009;92(2):198-207.

3. Wallmuller C, Meron G, Kurkciyan I, Schober A, Stratil P, Sterz F. Causes of in-hospital cardiac arrest and influence on outcome. Resuscitation. 2012;83(10):1206-1211.

4. Pattana K. Perioperative mortality in BuddhachinarajPhitsanulok Hospital. Buddhachinaraj Medical Journal. 2008;25(2):581-586.

5. Ahmed A, Ali M, Khan EA, Khan MU. An audit of perioperative cardiac arrests in a Southeast Asian university teaching hospital over 15 years. Anaesth Intensive Care. 2008;36(5):710-716.

6. An JX, Zhang LM, Sullivan EA, Guo QL, Williams JP. Intraoperative cardiac arrest during anesthesia: a retrospective study of 218,274 anesthetics undergoing non-cardiac surgery. Chin Med J (Engl) 2011;124(2):227-232.

7. Ahmed A, Ali M, Khan M, Khan F. Perioperative cardiac arrests in children at a university teaching hospital of a developing country over 15 years. Paediatr Anaesth. 2009;19(6):581-586.

8. Charuluxananan S, Thienthong S, Rungreungvanich M, et al. Cardiac arrest after spinal anesthesia in Thailand: a prospective multicenter registry of 40,271 anesthetics. Anesth Analg. 2008;107(5):1735-1741.

9. Zuercher M, Ummenhofer W. Cardiac arrest during anesthesia. Curr Opin Crit Care. 2008;14(3):269-274.

10. Bainbridge D, Martin J, Arango M, Cheng D. Perioperative and anaesthetic-related mortality in developed and developing countries: a systematic review and meta-analysis. Lancet. 2012;380(9847): 1075-1081.

11. Siriphuwanun V, Punjasawadwong Y, Lapisatepun W, Charuluxananan S, Uerpairojkit K, Patumanond J. The initial success rate of cardiopulmonary resuscitation and its associated factors in patients with cardiac arrest within 24 hours after anesthesia for an emergency surgery. Risk Manag Healthc Policy. 2014;7:65-76.

12. Dabrowska A, Telec W. [New guidelines of Basic and Advanced Cardiopulmonary Resuscitation and Emergency Cardiovascular Care (ECC) American Heart Association (AHA)]. Wiad Lek. 2011;64(2): 127-131. Polish.

13. Thavat C, Piyawan S, Sasikaan N. Outcome of in-hospital cardiopulmonary resuscitation and factors affecting the outcome at Songklanagarind Hospital. Songkla Med J. 2011;29(1):39-49.

14. Khan NU, Razzak JA, Ahmed H, et al. Cardiopulmonary resuscitation: outcome and its predictors among hospitalized adult patients in Pakistan. Int J Emerg Med. 2008;1:27-134.

15. Rodriguez-Nunez A, Lopez-Herce J, Garcia C, et al. Effectiveness and long-term outcome of cardiopulmonary resuscitation in paediatric intensive care units in Spain. Resuscitation. 2006;71(3):301-309.

16. Lin YR, Wu HP, Huang CY, Chang YJ, Lin CY, Chou CC. Significant factors in predicting sustained ROSC in paediatric patients with traumatic out-of-hospital cardiac arrest admitted to the emergency department. Resuscitation. 2007;74(1):83-89.

17. International Liaison Committee on Resuscitation. 2005 International Consensus on Cardiopulmonary Resuscitation and Emergency Cardiovascular Care Science with Treatment Recommendations. Part 4: Advanced life support. Resuscitation. 2005;67:213-247.

18. Goswami S, Brady JE, Jordan DA, Li G. Intraoperative cardiac arrests in adults undergoing noncardiac surgery: incidence, risk factors, and survival outcome. Anesthesiology. 2012;117(5):1018-1026.

19. Fitzgerald M, Spencer J, Johnson F, Marasco S, Atkin C, Kossmann T. Definitive management of acute cardiac tamponade secondary to blunt trauma. Emerg Med Australas. 2005;17(5-6):494-499.
20. Bamvita JM, Bergeron E, Lavoie A, Ratte S, Clas D. The impact of premorbid conditions on temporal pattern and location of adult blunt trauma hospital deaths. J Trauma. 2007;63(1):135-141.

21. Leidel BA, Kanz KG, Kirchhoff C, Burklein D, Wismuller A, Mutschler W. Kreislaufstillstand nach stumpfem Thoraxtrauma [Cardiac arrest following blunt chest injury. Emergency thoracotomy without ifs or buts?]. Unfallchirurg. 2007;110(10):884-890. German.

22. Pipanmekaporn T, Bunchungmonkol N, Chuaratanaphong $\mathrm{S}$, Punjasawadwong Y, Saringcaringkul A, Sawaddiruk P. Perioperative mortality and risk factors in cardiac surgery, a review of 3,822 cases at the northern cardiac center, Thailand. Chiang Mai Med J. 2009;48(1): $15-24$.

23. Arenal JJ, Bengoechea-Beeby M. Mortality associated with emergency abdominal surgery in the elderly. Can J Surg. 2003;46(2):111-116.

24. Harrington DT, Phillips B, Machan J, et al. Factors associated with survival following blunt chest trauma in older patients: results from a large regional trauma cooperative. Arch Surg. 2010;145(5):432-437.

25. Suraseranivongse $\mathrm{S}$, Chawaruechai $\mathrm{T}$, Saengsung $\mathrm{P}$, Komoltri C. Outcome of cardiopulmonary resuscitation in a 2300-bed hospital in a developing country. Resuscitation. 2006;71(2):188-193.

26. Krittayaphong R, Saengsung P, Chawaruechai T, Yindeengam A, Udompunturak S. Factors predicting outcome of cardiopulmonary resuscitation in a developing country: the Siriraj cardiopulmonary resuscitation registry. J Med Assoc Thai. 2009;92(5):618-623.

27. Rodanant O, Hintong T, Chua-in W, Tanudsintum S, Sirinanmd C, Kyokong O. The Thai anesthesia incidents study (THAI Study) of perioperative death in geriatric patients. J Med Assoc Thai. 2007;90(7): $1375-1381$.

28. Jintapakorn W, Tasanapitak J, Intaraksa P. Results of cardiopulmonary resuscitation (CPR) at Songklanagarind Hospital. Songkla Med J. 2005;23(Supp12):223-227.

29. Bunchungmongkol N, Punjasawadwong Y, Chumpathong S, et al. Anesthesia-related cardiac arrest in children: the Thai Anesthesia Incidents Study (THAI Study). J Med Assoc Thai. 2009;92(4): 523-530.

30. Faucher A, Savary D, Jund J, Carpentier F, Payen JF, Danel V. Optimiser la réanimation des arrêts cardiaques traumatiques préhospitaliers: l'expérience d'un registre prospectif [Optimize the resuscitation of prehospital cardiac arrest in trauma patients: a prospective register's experience]. Ann Fr Anesth Reanim. 2009;28(5):442-447. French.

31. Sandroni C, Nolan J, Cavallaro F, Antonelli M. In-hospital cardiac arrest: incidence, prognosis and possible measures to improve survival. Intensive Care Med. 2007;33(2):237-245.

32. Gonzalez LP, Pignaton W, Kusano PS, Modolo NS, Braz JR, Braz LG. Anesthesia-related mortality in pediatric patients: a systematic review. Clinics (Sao Paulo). 2012;67(4):381-387.

33. Braz LG, Braz DG, Cruz DS, Fernandes LA, Modolo NS, Braz JR. Mortality in anesthesia: a systematic review. Clinics (Sao Paulo). 2009;64(10):999-1006.

34. Bharti N, Batra YK, Kaur H. Paediatric perioperative cardiac arrest and its mortality: database of a 60-month period from a tertiary care paediatric centre. Eur J Anaesthesiol. 2009;26(6):490-495.

35. Olotu A, Ndiritu M, Ismael M, et al. Characteristics and outcome of cardiopulmonary resuscitation in hospitalised African children. Resuscitation. 2009;80(1):69-72.

36. Chan JC, Wong TW, Graham CA. Factors associated with survival after in-hospital cardiac arrest in Hong Kong. Am J Emerg Med. 2013;31(5): 883-885.

37. Sittichanbuncha Y, Prachanukool T, Sawanyawisuth K. A 6-year experience of CPR outcomes in an emergency department in Thailand. Ther Clin Risk Manag. 2013;9:377-381.

38. Rea TD, Cook AJ, Stiell IG, et al. Predicting survival after out-ofhospital cardiac arrest: role of the Utstein data elements. Ann Emerg Med. 2009;55(3):249-257.

39. Meaney PA, Nadkarni VM, Kern KB, Indik JH, Halperin HR, Berg RA. Rhythms and outcomes of adult in-hospital cardiac arrest. Crit Care Med. 2009;38(1):101-108. 
40. Cooper S, Janghorbani M, Cooper G. A decade of in-hospital resuscitation: outcomes and prediction of survival? Resuscitation. 2006;68(2):231-237.

41. Lee HK, Lee H, No JM, et al. Factors influencing outcome in patients with cardiac arrest in the ICU. Acta Anaesthesiol Scand. 2013;57(6): 784-792.

42. Bradley SM. Update in cardiopulmonary resuscitation. Minerva Cardioangiol. 2011;59(3):239-253.

43. Pembeci K, Yildirim A, Turan E, et al. Assessment of the success of cardiopulmonary resuscitation attempts performed in a Turkish university hospital. Resuscitation. 2006;68(2):221-229.
44. Rujada S, Waralee A. Survival outcome of Out-of-hospital cardiac arrest in Emergency Medical Service. Royal Thai Air Force Medical Gazette. 2011;57(3):20-25.

45. Lundy DJ, Ross SE, Schorr C, Jones AE, Trzeciak S. Outcomes of trauma victims with cardiac arrest who survive to intensive care unit admission. J Trauma. 2011;71(1):E12-E16.

46. Siriphuwanun V, Punjasawadwong Y, Lapisatepun W, Charuluxananan S, Uerpairojkit K. Incidence of and factors associated with perioperative cardiac arrest within 24 hours of anesthesia for emergency surgery. Risk Manag Healthc Policy. 2014;7:155-162.

\section{Publish your work in this journal}

Risk Management and Healthcare Policy is an international, peerreviewed, open access journal focusing on all aspects of public health, policy, and preventative measures to promote good health and improve morbidity and mortality in the population. The journal welcomes submitted papers covering original research, basic science, clinical \& epidemio- logical studies, reviews and evaluations, guidelines, expert opinion and commentary, case reports and extended reports. The manuscript management system is completely online and includes a very quick and fair peerreview system, which is all easy to use. Visit http://www.dovepress.com/ testimonials.php to read real quotes from published authors. 